\title{
Hispanic Population of Child-Bearing Age Grows, but Births Diminish
}

\author{
Kenneth M. Johnson
}

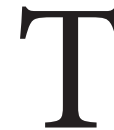

The U.S. population grew by just 0.62 percent last year, the smallest rate of increase in eighty years. Future growth now depends on minority population gains, because the white population is no longer growing. Hispanics are the largest minority group and now account for the majority of U.S. population gain. Though much attention focuses on immigration, nearly 70 percent of the Hispanic population gain occurred because births far exceed deaths. Yet in 2017, there were just 899,000 Hispanic births, 164,000 fewer than a decade ago, even though there are now 2.4 million more Hispanic women of child-bearing age than in 2007. Hispanic births diminished by 15 percent despite this 22 percent increase in child bearing age women because the Hispanic fertility rate declined by 31 percent between 2007 and 2017. This dramatic decline in Hispanic fertility has significant implications. If it is sustained, Hispanic women would be expected to have approximately two children each compared to an expectation of about three each in 2007 . The fertility reductions have been greatest among teenagers and women in their 20s, so some births may be delayed rather than foregone. The Hispanic child-bearing age population will continue to increase, so how many children Hispanic women eventually decide to have will significantly impact future U.S. population growth.

\section{HISPANIC FERTILITY TRENDS, 2007 TO 2017}

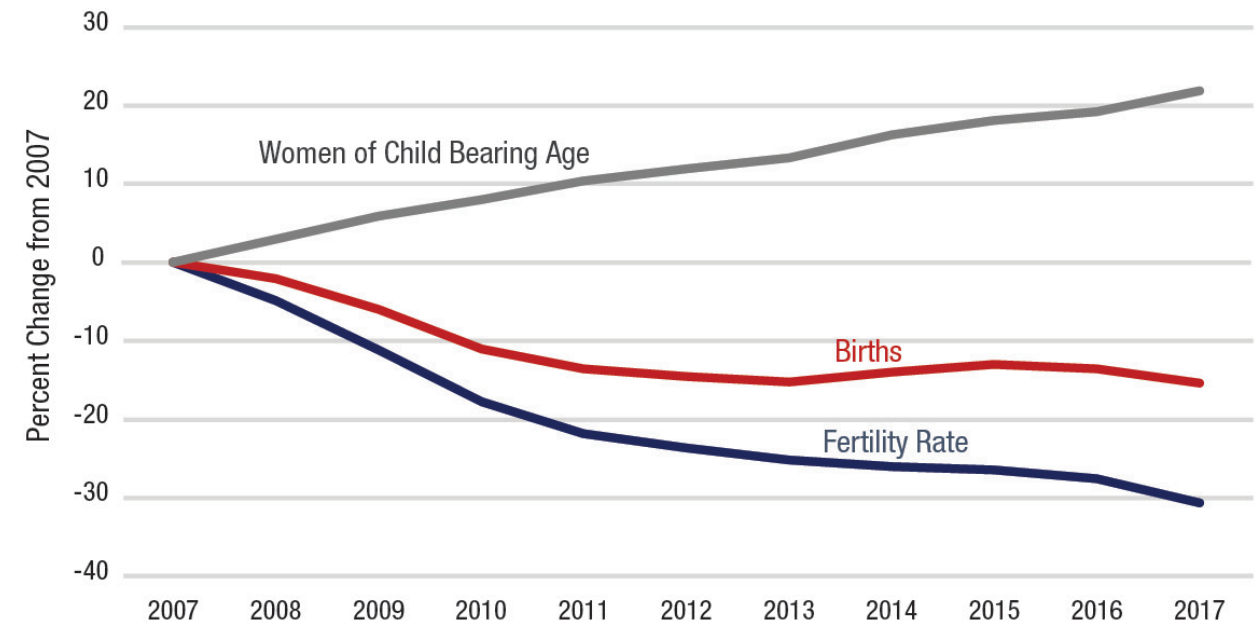

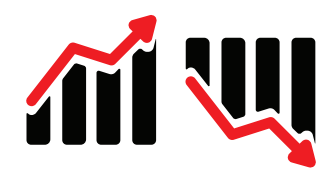

The Hispanic population of child-bearing age is growing, but fewer Hispanic babies are being born.

\section{See Related Publications at carsey.unh.edu}

- U.S. Population Growth Continues to Slow Due to Fewer Births and More Deaths, December 2018

- Domestic Migration and Fewer Births Reshaping America, March 2018

\section{About the Author \\ Kenneth M. Johnson is Senior Demographer at the Carsey School of Public Policy, Class of 1940 Professor of Sociology at the University of New Hampshire, and an Andrew Carnegie Fellow. This research was supported by his Andrew Carnegie Fellowship. The content is solely the responsibility of the author and does not necessarily represent the official view of the sponsoring organization.}

Source: CDC-National Center for Health Statistics. Note: Fertility rate is births/1,000 women 15-44.

Huddleston Hall • 73 Main Street • Durham, NH 03824 carsey.unh.edu $\bullet 603.862 .2821$
TTY USERS: DIAL 7-1-1 OR 1-800-735-2964 (RELAY N.H.) 